\title{
Influence of $\mathrm{SrF}_{2}$-doping in $\mathrm{AlN}$ ceramics on
}

\section{Scintillation and Dosimeter Properties}

\author{
Kaori Kojima ${ }^{\text {a, }}$, Go Okada ${ }^{\text {a }}$, Kentaro Fukuda ${ }^{\text {, }}$, Takayuki Yanagida ${ }^{\text {a }}$ \\ ${ }^{a}$ Graduate School of Materials Science, Nara Institute of Science and Technology, 8916-5 Takayama, Ikoma, Nara 630- \\ 0192, JAPAN \\ ${ }^{b}$ Tokuyama Corp., 1-1 Mikage-cho, Shunan-shi, Yamaguchi 745-8648, JAPAN
}

\begin{abstract}
Abstarct
In this study, we synthesized undoped $\mathrm{AlN}$ and $\mathrm{SrF}_{2}$-doped $\mathrm{AlN}\left(\mathrm{AlN}-\mathrm{SrF}_{2}\right)$ ceramics by Spark Plasma Sintering (SPS), and we characterized their optical, scintillation and dosimeter properties. The prepared undoped AlN ceramic had gray color and visually non-transparent whereas, with an addition of $\mathrm{SrF}_{2}$, the transparency improved and became translucent. The measured in-line transmittance was approximately $0.2 \%$ at wavelengths longer than $500 \mathrm{~nm}$. While the addition of $\mathrm{SrF}_{2}$ decreased the scintillation intensity, the decay time was significantly fastened, which is a great advantage for fast photon counting-based measurements. Both the thermally-stimulated luminescence (TSL) and optically-stimulated luminescence (OSL) showed good linear response from the milli-gray range to over $10 \mathrm{~Gy}$. The sensitivity seems to decrease by an addition of $\mathrm{SrF}_{2}$ as it suppresses structural defect centers which are responsible for dosimeter properties. However, the main TSL glow peak position shifts to higher temperature with the addition of $\mathrm{SrF}_{2}$, which indicates that inclusion of $\mathrm{SrF}_{2}$ improves the TSL signal stability.

Key-words: X-ray, dosimeter, Scintillation, AlN, Thermally Stimulated Luminescence, Optically Stimulated Luminescence.
\end{abstract}




\section{Introduction}

Ionizing radiation detectors are currently widely applied in many fields; for example, physics, medicine and geology. Those radiation detectors often use solid states luminescent materials, which are known as scintillators and dosimeters. A scintillators absorbs an incident ionizing radiation and immediately converts the energy into thousands of low energy photons such as UV/Vis/NIR light via energy migration from the host to emission centers (Yanagida et al., 2013). On the other hand, a dosimeter material absorbs and accumulates the incident radiation energy as a form of trapped carriers. These carriers can be de-trapped by an optical or thermal stimulation, which is followed by a light emission. These emissions are often referred as an optically-stimulated luminescence (OSL) (McKeever, 1985) and thermally-stimulated luminescence (TSL) (Yukihara et al., 2011), respectively. Some examples of practical TSL dosimeter materials are Mg- and Ti-doped LiF (Mayhugh et al., 1970), and carbondoped aluminum oxide $\left(\mathrm{Al}_{2} \mathrm{O}_{3}: \mathrm{C}\right)$ is a particularly well-known OSL dosimeter (McKeever, 2011).

AlN has a highly covalent-bonded wurtzite crystal structure and wide bandgap $\left(\mathrm{E}_{\mathrm{g}}=6.2 \mathrm{eV}\right)$. One of the practical applications of AlN is a heat sink due to its high thermal conductivity $\left(320 \mathrm{~W} \mathrm{~m}^{-1} \mathrm{~K}^{-1}\right)$ with high electrical insulation properties. Also, AlN is an attractive semiconductor material to be used for UV-LED (Taniyasu et al., 2006). Furthermore, in the previous work, we have shown that an AlN ceramic plate, which is a commercial product as a heat sink, is applicable for TSL and OSL dosimeter applications (Yanagida et al., 2013a; Okada et al., 2015). For dosimeter applications, the detector materials are preferably those with the effective atomic number $\left(Z_{\text {eff }}\right)$ equivalent to human tissue $\left(Z_{\text {eff }} \sim 7.4\right)$. Tissue equivalent dosimeter material interact with radiations as in actual tissue, so any post-irradiation corrections (often done mathematically) are required. In this point of view, AlN is an attractive material as the $\mathrm{Z}_{\text {eff }}$ of $\mathrm{AlN}$ is 11.7 and very close to the $\mathrm{Z}_{\text {eff }}$ of $\mathrm{Al}_{2} \mathrm{O}_{3}$ (11.3) which is one of the most widely used tissue-equivalent dosimeter materials. For those reasons, AlN is of our particular interest as a potential dosimeter material. In addition, earlier studies have shown that doping of $\mathrm{CaF}_{2}$ to $\mathrm{AlN}$ improves some properties such as the densification process (Xiong et al., 2013), thermal conductivity (Qiao et al., 2003; He et al., 2010) and optical transmittance (Xiong et al., 2005; Xiong et al., 2006). Strontium and calcium 
are members of the alkaline earth metals, and they share similar physiologic and chemical properties (Chi, 1979)

In this study, we prepared undoped $\mathrm{AlN}$ and $\mathrm{SrF}_{2}$-doped AlN by the Spark Plasma Sintering (SPS) (Tokita, 1999) and studied the effects on the optical and dosimeter properties of AlN in relation with an addition of $\mathrm{SrF}_{2}$.

\section{Experimental procedure}

The undoped and $\mathrm{SrF}_{2}$ doped AlN ceramics were synthesized by SPS. The doping concentrations of $\mathrm{SrF}_{2}$ were 1, 2 and 5 wt.\%. In this paper, the $\mathrm{SrF}_{2}$-doped AlN samples are denoted as AlN-SrF 2 . The starting raw materials of $\mathrm{AlN}$ and $\mathrm{SrF}_{2}$ were supplied by Tokuyama Corp. These compounds were mixed homogeneously, and the mixture of $0.5 \mathrm{~g}$ batch was loaded into a cylinder graphite die with the inner diameter of $10 \mathrm{~mm}$, which was sealed by inserting two punches inside the die. This assembly was next loaded to the SPS furnace (La-BOX110, Sinter Land) to sinter at $1800{ }^{\circ} \mathrm{C}$ for 15 min under $3 \mathrm{kN}$ pressure. The obtained sample size was typically $10 \mathrm{~mm} \Phi \times 1 \mathrm{mmt}$, and the sample surfaces were polished for characterizations.

The microstructures of samples were observed by using a scanning electron microscope (SEM; Hitachi S-3400). The photoluminescence (PL) emission spectrum and PL-decay were measured by using Hamamatsu Quantaurus- $\tau$. For both the measurements, the excitation wavelength was $280 \mathrm{~nm}$, and the monitoring wavelengths of PL decay were 330, 500 and $600 \mathrm{~nm}$.

The Scintillation spectra were evaluated at room temperature under X-ray irradiation by utilizing our original setup (Yanagida et al., 2013b). The irradiation source was an X-ray generator (Spellman, XRB80P \& N200X4550) equipped with W target (OURSTEX Corporation) supplied with $80 \mathrm{kV}$ DC voltage and $2.5 \mathrm{~mA}$ tube current. The emission spectra were digitized by using Andor DU-920-BU2 CCD spectrometer (cooled at $188 \mathrm{~K}$ by a Peltier module) equipped with a monochromator SR163 (Andor, 1200 grooves/mm and $300 \mathrm{~nm}$ blaze wavelength). The scintillation light was fed into the spectrometer through a $2 \mathrm{~m}$ optical fiber. The scintillation decay time was separately measured by our original setup, a pulsed X-ray equipped afterglow characterization system (Yanagida et al., 2014) having a timing 
resolution of $\sim 1 \mathrm{~ns}$. In this measurement, all the emission wavelengths were integrated and digitized by the PMT. The spectral sensitivity of the system was from 160 to $650 \mathrm{~nm}$, which covers the entire emission range of AlN.

As a dosimeter property, the TSL glow curves after X-ray irradiation $\left(1-10^{4} \mathrm{mGy}\right)$ were evaluated by using TL-2000 (Nano Gray) (Yanagida et al., 2013a). The photodetector installed in the reader has a sensitivity over $300-500 \mathrm{~nm}$. The heating rate was $1{ }^{\circ} \mathrm{C} / \mathrm{s}$. Prior to a TSL measurement, a sample was irradiated by X-rays using the same generator used for the RL measurement described above. The X-ray dose was calibrated by the ionization chamber (TN30013, PTW). The OSL was measured by using Hamamatsu Quantaurus- $\tau$. The stimulation light source used here was a $630 \mathrm{~nm}$ LED. The LED equipped in this instrument is very stable which allows us to measure the OSL response with a high reproducibility. The X-ray irradiation was performed in the same manner as in the TSL measurements described above.

\section{Results and discussion}

Fig. 1 shows the AlN ceramic samples doped with $0,1,2$ and $5 \%$ of $\mathrm{SrF}_{2}$. The undoped sample has gray/green color without any visual evidence of optical transparency. On the other hand, $\mathrm{AlN}-\mathrm{SrF}_{2}(1,2$ and $5 \%$ ) were translucent and the strip patterns behind the samples can be clearly seen through. Interestingly, the outer edge of only $\mathrm{AlN}_{-} \mathrm{SrF}_{2}(2 \%)$ was blue, and the rest were gray color. Fig. 2 illustrates SEM images of selected samples: $\mathrm{AlN}$ and $\mathrm{AlN}_{-} \mathrm{SrF}_{2}(5 \%)$. The grain sizes were estimated to be several $\mu \mathrm{m}$, and the grain size is larger when $\mathrm{SrF}_{2}$ is added.

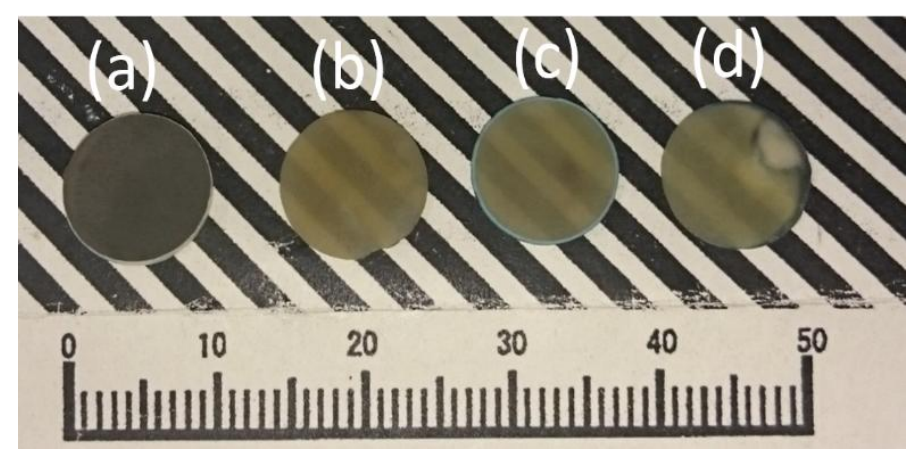


Fig. 1 Synthesized (a) undoped and AlN-SrF ${ }_{2}$ ceramics samples. The concentrations of $\mathrm{SrF}_{2}$ are (b) 1 , (c) 2 and (d) $5 \%$.
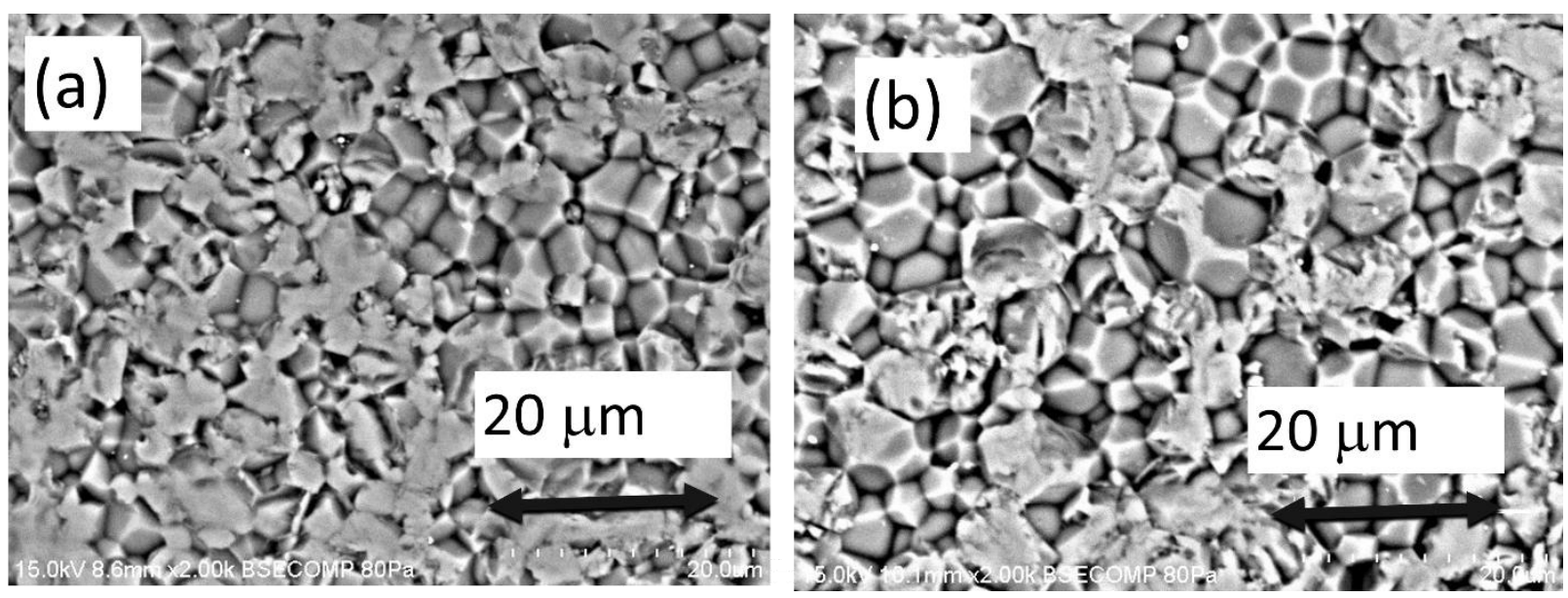

Fig.2 SEM images of (a) undoped AlN and (b) $\mathrm{AlN}_{-} \mathrm{SrF}_{2}(5 \%)$ ceramics synthesized by SPS.

Fig. 3 shows the optical in-line transmittance spectra of $\mathrm{AlN}-\mathrm{SrF}_{2}$ samples. The distortion seen around $800 \mathrm{~nm}$ was an instrumental artifact caused by switching of diffraction grating and lamp. The transmittance was approximately $0.2 \%$ at wavelengths longer than $500 \mathrm{~nm}$. This value is not so high compared with an earlier work (Honma et al., 2008), in which AlN ceramics have shown to be translucent with an addition of $\mathrm{Ca}_{2} \mathrm{Al}_{2} \mathrm{O}_{6}$. 


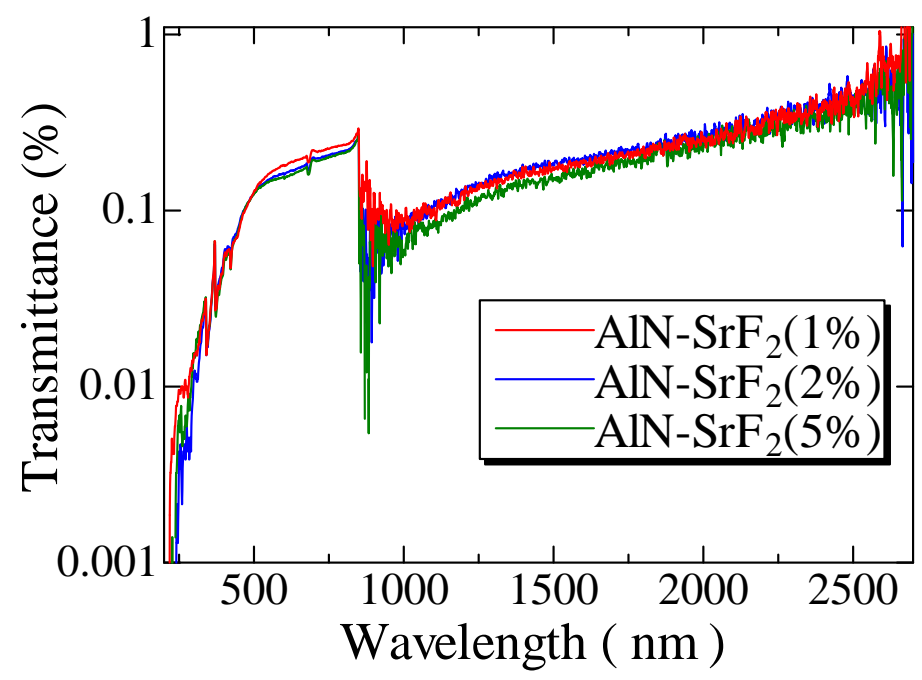

Fig.3 Transmittance spectra of 1-5\% AlN-SrF 2 .

The PL of undoped AlN appeared around $400 \mathrm{~nm}$ with a very broad structure. In contrast, earlier works (Sun et al., 2001; Matoussi et al., 2010) have shown emissions around 505 and $550 \mathrm{~nm}$. Interestingly enough, we did not observe the same emissions in our AlN sample. It is possible that these emissions are related to some defects and oxygen impurities which are strongly affected by the preparation method and starting materials. In our case, any oxide materials were used, and the sintering was performed under a strong vacuum environment. Instead, $\mathrm{AlN}-\mathrm{SrF}_{2}$ samples showed other emissions around 330, 500 and $600 \mathrm{~nm}$, which were not observed in the undoped AlN sample. Therefore, we assign these emissions due to some additional defects created by doping with $\mathrm{SrF}_{2}$. 


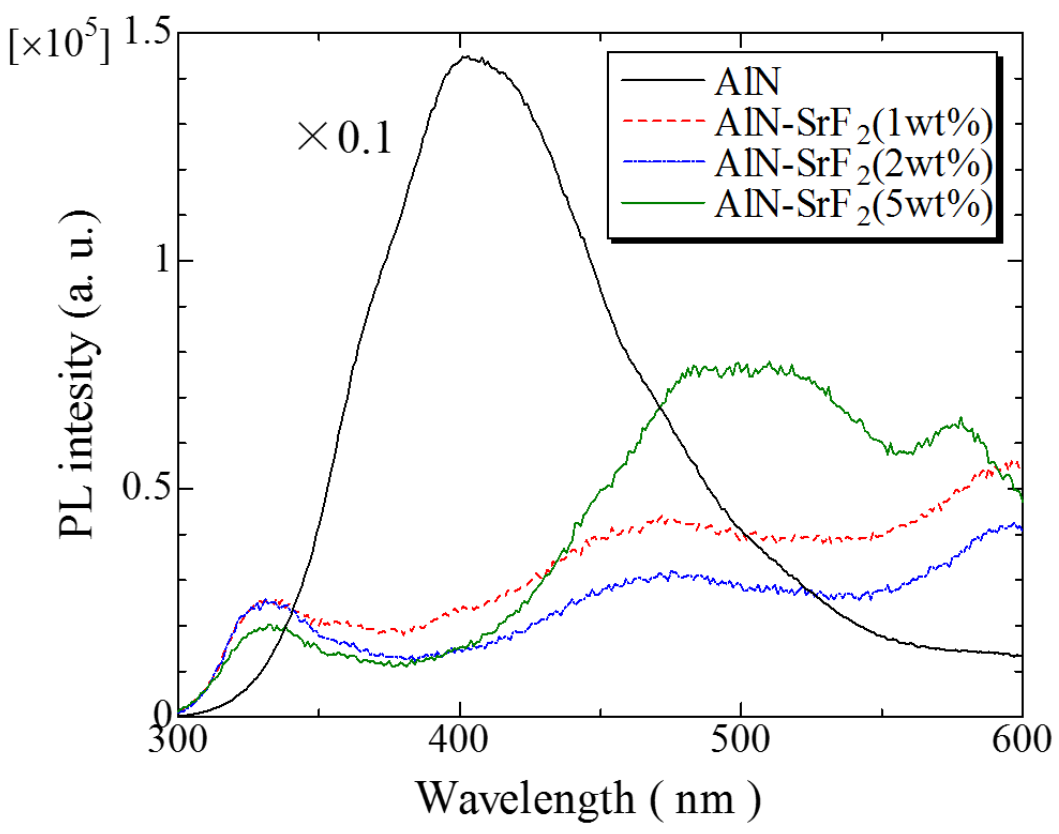

Fig.4 PL spectra of AlN and AlN-SrF 2 ceramic samples under $280 \mathrm{~nm}$ excitation.

PL-decay time profiles of 405, 490 and $595 \mathrm{~nm}$ emission bands are displayed in Fig.5.

To quantify the decay curves, they were fitted with a sum of exponential decay functions as:

$$
I=\sum_{i=1}^{n} A_{i} \exp \left(-t / \tau_{i}\right)
$$

where $\tau_{i}$ is the decay time constant and $A_{i}$ is emission intensity at $t=0$. For PL decay, the number of decay term was selected to be $2(n=2)$.

The fast decay time around $1 \mathrm{~ns}$ is due to the instrumental response. The obtained PL-decay times are summarized in Table 1. All the samples show relatively fast lifetime of a few ns. The lifetime at $490 \mathrm{~nm}$ decreases with increasing the concentration of $\mathrm{SrF}_{2}$, but the other emissions were consistent regardless of the concentration of $\mathrm{SrF}_{2}$. 

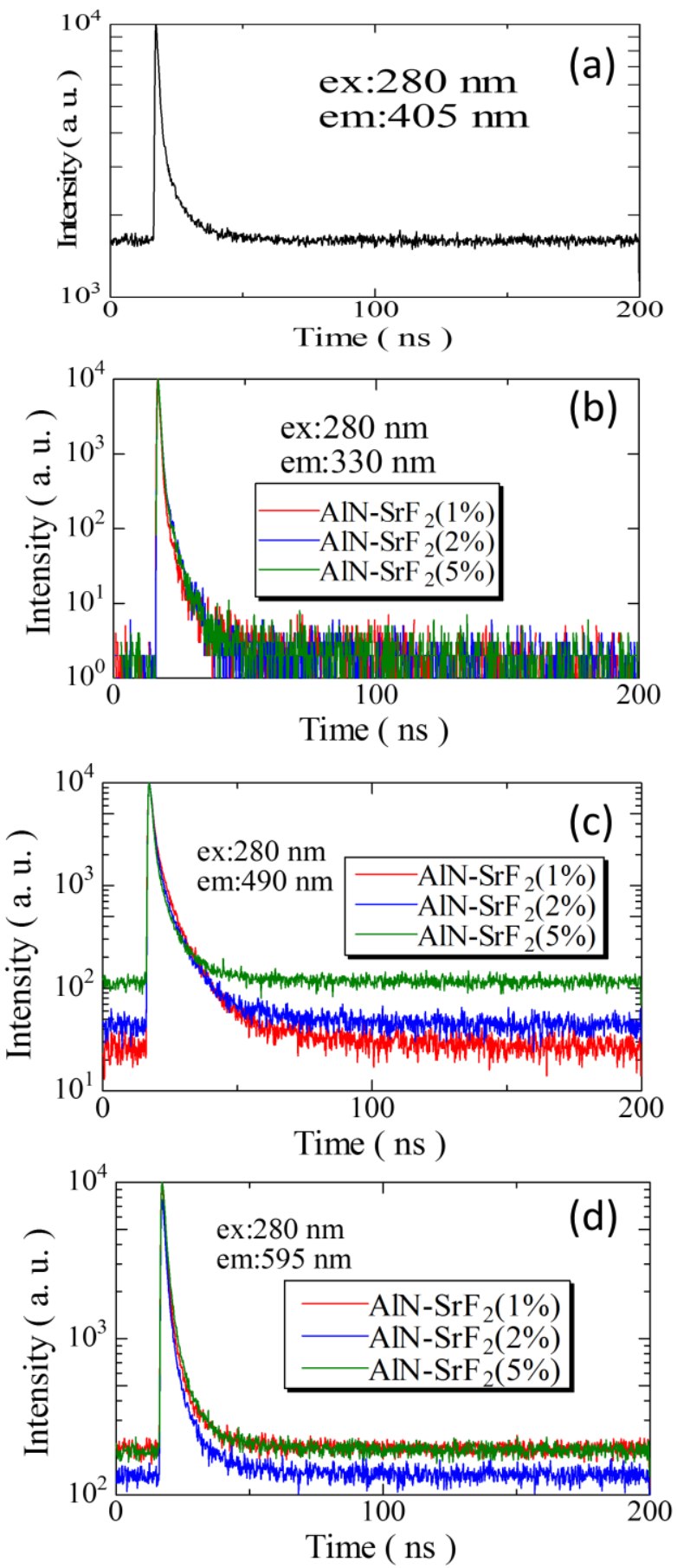

Fig.5 PL-decay time profiles of (a)AlN monitoring at $405 \mathrm{~nm}$, (b) $\mathrm{AlN}-\mathrm{SrF}_{2}(1-5 \%)$ monitoring at $330 \mathrm{~nm}$ (c) $\mathrm{AlN}-\mathrm{SrF}_{2}(1-5 \%)$ monitoring at $490 \mathrm{~nm}$ and (d) $\mathrm{AlN}_{-} \mathrm{SrF}_{2}(1-5 \%)$ monitoring at $595 \mathrm{~nm}$ under $280 \mathrm{~nm}$ excitation. 
Table 1 Summary of PL decay times measured. The excitation wavelength is $280 \mathrm{~nm}$.

\begin{tabular}{ccccc}
\hline \hline \multirow{2}{*}{$\lambda_{\mathrm{em}}(\mathrm{nm})$} & $\mathrm{AlN}(\mathrm{ns})$ & \multicolumn{3}{c}{$\mathrm{AlN}_{\mathrm{S} S \mathrm{Sr}}(\mathrm{ns})$} \\
\cline { 3 - 5 } & & $1 \%$ & $2 \%$ & $5 \%$ \\
\hline 330 & - & 2.7 & 2.7 & 2.4 \\
400 & 6.2 & - & - & - \\
490 & - & 6.2 & 5.5 & 4.7 \\
595 & - & 4.4 & 4.6 & 4.7 \\
\hline \hline
\end{tabular}

Fig. 6 shows the radioluminescence spectra of undoped and $\mathrm{AlN}-\mathrm{SrF}_{2}$ ceramic samples. The emission peak of the undoped $\mathrm{AlN}$ appeared around $380 \mathrm{~nm}$ with a very broad feature. By an addition of $\mathrm{SrF}_{2}$, the emission intensity of this peak decreased by a factor of approximately 7 or larger, and the emission peak appeared around 350, 450 and $600 \mathrm{~nm}$. These tendencies were similar with those in PL.

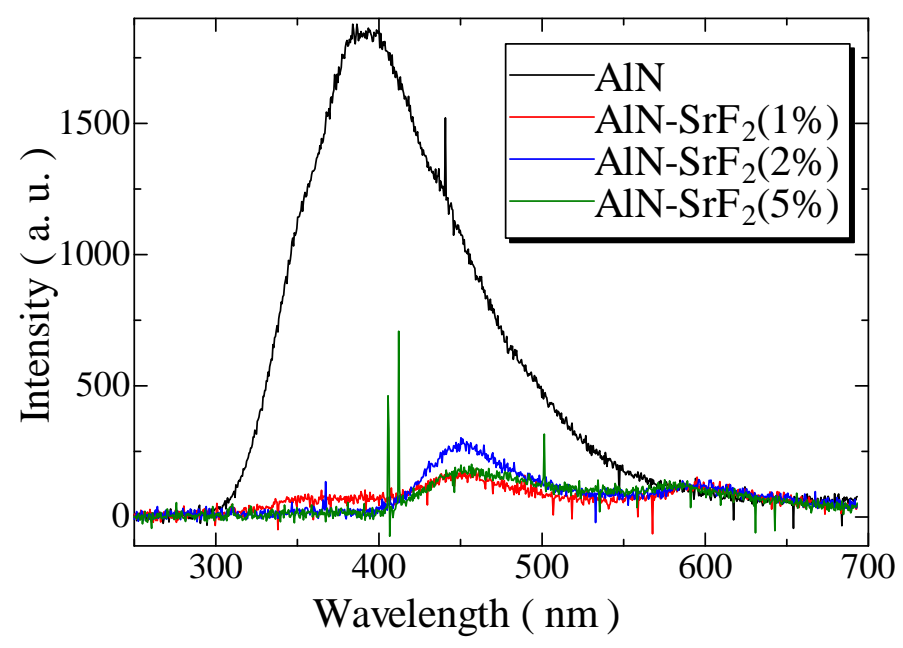

Fig.6 X-ray induced emission spectra of the samples.

The scintillation decay time profiles are shown in Fig. 7. Their curves were fitted by Equation (2) with three exponential terms $(n=3)$ to extract decay times. The obtained scintillation decay times are summarized in Table 2. 
Both undoped AlN and $\mathrm{AlN}-\mathrm{SrF}_{2}$ (1-5\%) show fast decays. As observed for the $490 \mathrm{~nm}$ emission in PL, the decay time decreases with increasing the $\mathrm{SrF}_{2}$ concentration. However, due to the energy transportation process involved in the scintillation process, the scintillation decay time was slower than that of PL. It is instructive to note here that the energy transfer process is referred as, in general, migration of electrons and holes generated by interacting with radiations into luminescent centers. In PL, only luminescent centers are directly excited so the above transportation process is not involved. Therefore, scintillation decay time was slower than that of PL.

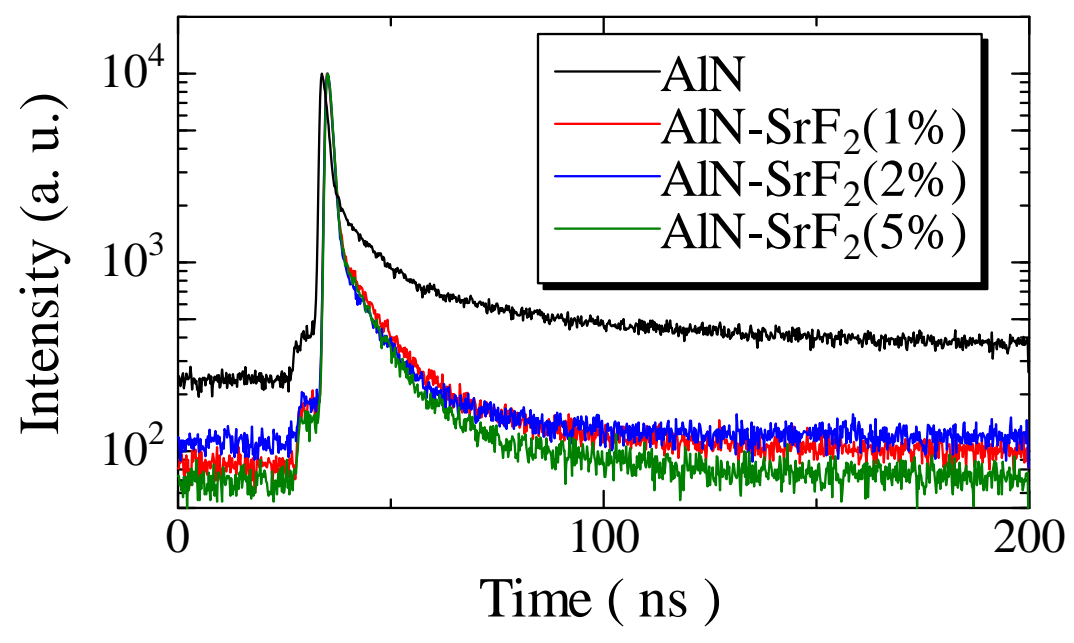

Fig.7 Scintillation decay time profiles of undoped AlN and $\mathrm{AlN}_{-} \mathrm{SrF}_{2}(1-5 \%)$.

Table 2 Summary of scintillation decay times measured

\begin{tabular}{ccccc}
\hline \hline & & & \multicolumn{3}{c}{$\mathrm{AlN}$} & & & \\
& AlN (ns) & & & \\
\cline { 3 - 5 } & & $1 \%$ & $2 \%$ & $5 \%$ \\
\hline$\tau_{1}$ & 9.8 & 10.4 & 9.6 & 9.1 \\
$\tau_{2}$ & 130.1 & 100.4 & 95.8 & 65.9 \\
\hline \hline
\end{tabular}


Fig.8 (left) shows TSL glow curves of AlN and $\mathrm{AlN}_{-} \mathrm{SrF}_{2}(1-5 \%)$. In the previous work (Yanagida et al., observed in our samples since this high temperature glow peak was due to an addition of sintering aids. By doping with $\mathrm{SrF}_{2}$, the TSL intensity decreased by a factor of approximately 200 or larger, and the glow peak shifted to higher temperature, from $\sim 160$ to $180{ }^{\circ} \mathrm{C}$. It indicates that a large amount of defects acting as shallow trapping centers in $\mathrm{AlN}$ are suppressed by doping with $\mathrm{SrF}_{2}$; as a result, charge carriers are only captured by deeper trapping centers. However, the population of the deeper trapping centers are much less than the shallow centers, so the measured TSL signal is much smaller. Nevertheless, the increase of glow peak temperature is an indication of improvement in the TSL stability. Since it is difficult for the charge carriers captured at deeper centers to escape at low temperature, such material can hold the dose information for longer term without fading. Fig.8 (right) shows the dose response curves of TSL by undoped $\mathrm{AlN}$ and $\mathrm{AlN}-\mathrm{SrF}_{2}(5 \%)$. For both the samples, a linear TSL response against the X-ray dose was confirmed. The dynamic range confirmed was from $1 \mathrm{mGy}$ to $10 \mathrm{~Gy}$ for the undoped AlN while $\mathrm{AlN}-\mathrm{SrF}_{2}$ did not show a measurable signal below $100 \mathrm{mGy}$.
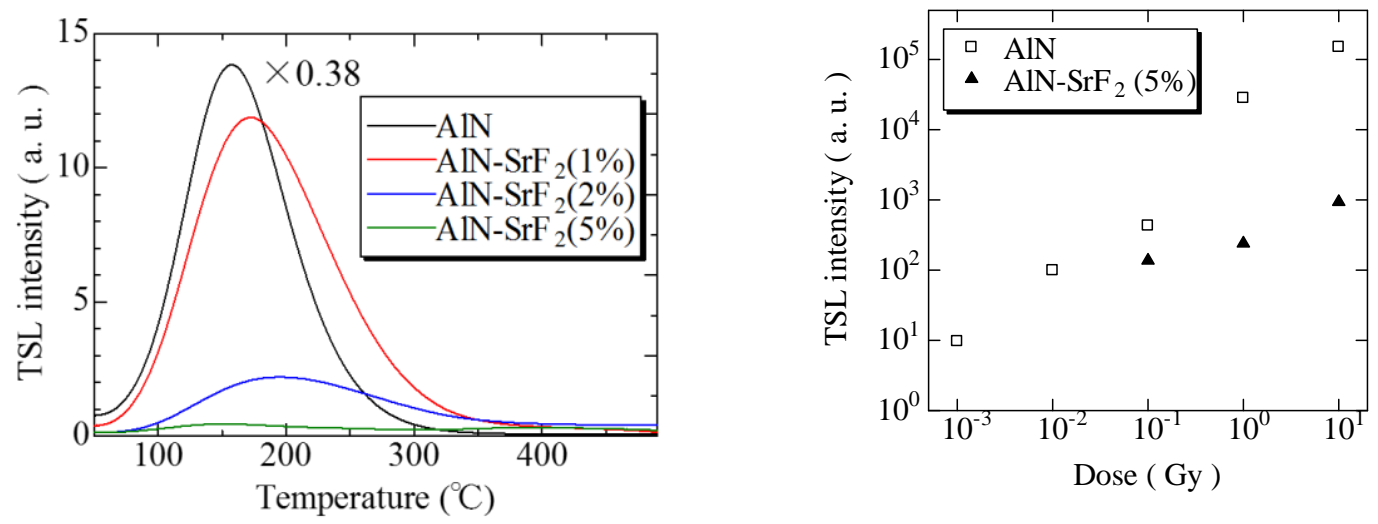

Fig.8 TSL glow curves (left) and dose response functions (right) of $\mathrm{AlN}$ and $\mathrm{AlN}-\mathrm{SrF}_{2}$ ceramics. The TSL glow curves were measured after an X-ray irradiation of $1 \mathrm{~Gy}$.

Fig.9 (left) shows the OSL spectra of undoped AlN and $\mathrm{AlN}_{-} \mathrm{SrF}_{2}(1 \%)$. For both the samples, the emission is very broad and the spectral position is very similar. The emission peak may be slightly 

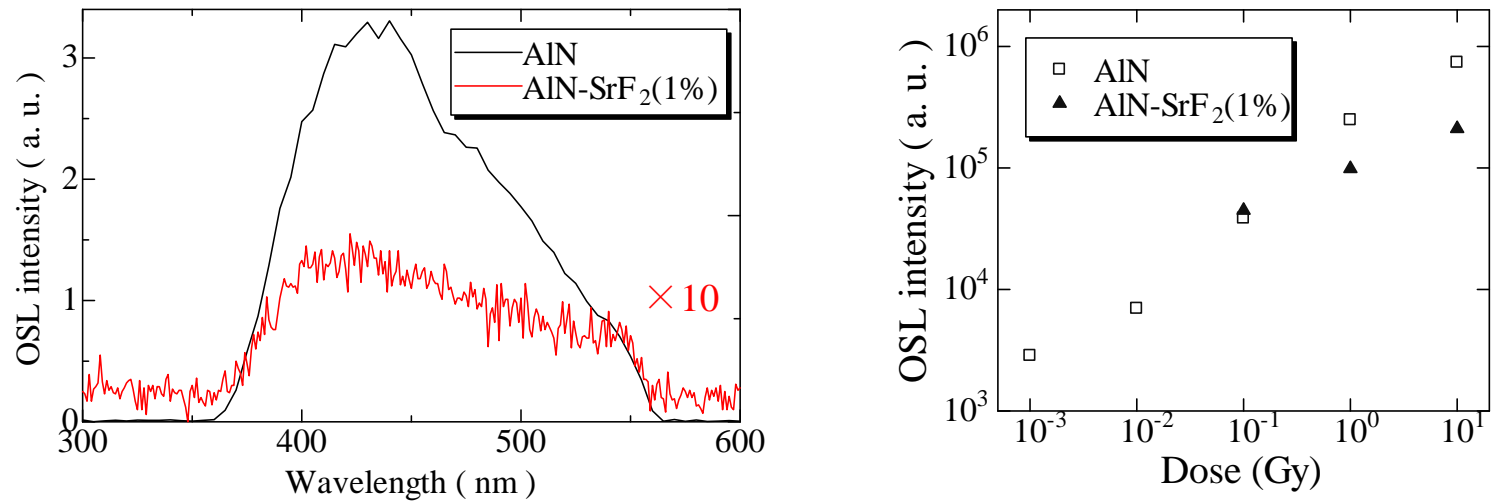

Fig.9 OSL emission spectra (left) and dose response functions (right) of $\mathrm{AlN}$ and $\mathrm{AlN}-\mathrm{SrF}_{2}$ ceramics. The stimulation light wavelength was $630 \mathrm{~nm}$. The emission spectra were measured after an X-ray irradiation of 10 Gy.

\section{Summary and Conclusions}

undoped AlN and $\mathrm{AlN}-\mathrm{SrF}_{2}(1,2$ and $5 \%)$ ceramics were synthesized by SPS. Although the undoped AlN sample was visually non-transparent and the in-line transmittance was not measurable, an addition of $\mathrm{SrF}_{2}$ improved the transmittance to $0.2 \%$ at the wavelengths longer than $500 \mathrm{~nm}$ and the opposite side of sample could be seen through with eye. Under UV and X-rays, PL and scintillation emissions, respectively, of undoped AlN ceramic sample appeared around $400 \mathrm{~nm}$ only. In contrast, an addition of $\mathrm{SrF}_{2}$ significantly changed the spectrum and showed PL and scintillation emission peaks around 330, 500 
and $600 \mathrm{~nm}$ and 350, 450 and $600 \mathrm{~nm}$, respectively. Also, the addition of $\mathrm{SrF}_{2}$ decreased the PL and scintillation decay times. Although the scintillation decay time was much longer than those in PL. In TSL, an addition of $\mathrm{SrF}_{2}$ increased the glow peak temperature (from $\sim 160{ }^{\circ} \mathrm{C}$ to $\sim 180{ }^{\circ} \mathrm{C}$ ), in other words a stability of TSL signal, at a cost of sensitivity. An OSL emission was observed in the undoped and AlN$\mathrm{SrF}_{2}(1 \%)$ around 460 and $430 \mathrm{~nm}$ by stimulation at $630 \mathrm{~nm}$. For those with a larger amount $\mathrm{SrF}_{2}$ added ( 2 and $5 \%$ ), no measurable signal was observed. Despite the reduced sensitively at lower doses, a linear response was confirmed up to $10 \mathrm{~Gy}$. For the future work, we will continue to optimize the AlN ceramics as a dosimeter with better sensitivity and stability.

\section{Acknowledgement}

This work was supported by a Grant in Aid for Scientific Research (A)-26249147 from the Ministry of Education, Culture, Sports, Science and Technology of the Japanese government (MEXT) and partially by JST A-step. Green Photonics Research from the MEXT and the Cooperative Research Project of Research Institute of Electronics, Shizuoka University, are also acknowledged. 
References

Chi T. C., 1979. Electrical resistivity of alkaline earth elements. J. Phys. Chem. Ref. Data. 8, 2, 439-497.

He X., Ye F., Zhang HJ., Zhou ZQ., 2010. Study on microstructure and thermal conductivity of Spark Plasma Sintering AlN ceramics. Mater. Design. 31, 4110-4115.

Honma T., Kuroki Y., Okamoto T., Takata M., Kanechika Y., Azuma M., Taniguchi H., 2008. Transmittance and cathodoluminescence of AlN ceramics sintered with Ca3Al2O6 as sintering additive. Ceram. Int. 34, 943-946.

Matoussi A., Nasr F. B., Boufaden T., Salh R., Fakhfakh Z., Guermazi S., EIJani B., Fitting H.-J., 2010. Luminescent properties of GaN films grown on porous silicon substrate. J. Lumin. 130, 399403.

Mayhugh M. R., Chrisy R. W., Johnson N. M., 1970. Thermoluminescence and Color Center Correlations in Dosimetry LiF. J. Appl. Phys. 41, 2968-2976.

McKeever .S.W.S., 2011. Optically stimulated luminescence. Radiat. Meas. 46, 1336-1341.

McKeever S. W.S, 1985. Thermoluminescence of Solids. Cambridge University Press.

Okada G., Fukuda K., Kasap S., Yanagida T., 2015. Opticaly Stimulated Luminescence of AlN Ceramics. Presented in IEEE NSS\&MIC, San Diego, USA, Oct. 31 - Nov. 7.

Qiao L., Zhou H., Fu R., 2003. Thermal conductivity of AlN ceramics sintered with CaF2 and YF3. Ceram. Int. 29, 893.

Sun J., Wu J., Ling H., Shi W., Ying Z. and Li F., 2001. Photoluminescence and its time evolution of AlN thin films. Phys. Lett. A. 280, 381-385.

Taniyasu Y., Kasu M., Makimoto T., 2006. An aluminium nitride light-emitting diode with a wavelength of 210 nanometres. Nature. 4, 325-328.

Tokita M., 1999. Trends in Advanced SPS System and FGM Technology. NEDO International Symposium on Functionally Graded Materials. Japan. 23-33

Trinkler L., Berzina B., 2001. Radiation induced recombination processes in AIN ceramics. J. Phys.: Condens. Matter. 13, 8931-8938 
Xiong Y., Fu Z., Wang H., Wang YC., Quan F., 2006. Fabrication of transparent AlN ceramics. J. Mater. Sci. $41,2537-2539$

Xiong Y., Fu Z.Y, Wang H., Wang Y. C., Zhang Q. J., 2005. Microstructure and IR transmittance of spark plasma sintering translucent AlN ceramics with CaF2 additive. Mater. Sci. Eng. B. 123, $57-62$

Xiong Y., Wang H., Fu Z., 2013. Transient liquid-phase sintering of AlN ceramics with CaF2 additive. J. European Ceram. Soc. 33, 2199-2205.

Yanagida T., Fujimoto Y., Ito T., Uchiyama K., Mori K., 2014. Development of X-ray-induced afterglow characterization system. Appl. Phys. Exp. 062401.

Yanagida T., Kamada K., Fujimoto Y., Yagi H. and Yanagitani T., 2013b. Comparative study of ceramic and single crystal Ce:GAGG scintillator. Opt. Mater. 35, 2480-2485

Yanagida T., Fujimoto Y., Kawaguchi N., Yanagida S., 2013a. Dosimeter properties of AlN. J. Ceram. Soc. Jpn. 121, 988.

Yanagida T., 2013. Study of rare-earth-doped scintillators. Opt. Mater. 35, 1987-1992.

Yukihara E. G., McKeever S. W. S., 2011. Optically Stimulated Luminescence: Fundamentals and Applications. John Wiley and Sons, Ltd. 